EPiC Series in Language and Linguistics
Volume 2, 2017, Pages 127-134
Professional and Academic Discourse:
an Interdisciplinary Perspective

\title{
Interdisciplinary Pedagogical Actions to Optimize Engineering Undergraduate Written Production
}

\author{
Alicia María Noceti, Carolina Chacón, Carlos Chiarella and Eduardo \\ Erbetta \\ Universidad Nacional de Entre Ríos, Argentina \\ nocetia@fcal.uner.edu.ar
}

\begin{abstract}
Writing is extremely challenging for engineering students. Navarro (2012) asserts that academic literacy in the mother tongue is similar to learning a foreign language as it involves immersion in a new culture. Food Engineering undergraduates (School of Food Science, University of Entre Ríos) face this difficulty when they have to write their Final Project. As a consequence, interdisciplinary actions were implemented by engineers and linguists (both in English and Spanish) in order to raise students' awareness of this genre characteristics, to facilitate its production and to write relevant titles and abstracts. The importance of both title and abstract is paramount once the Final Projects are uploaded to the university website in order to attract readers. The objective of this study was to explore whether interdisciplinary actions could optimize undergraduates' written production. All titles produced since the first Food Engineer graduated were collected. This corpus analysis revealed that titles were extremely short and provided very little information. Consequently, pedagogical activities were designed and implemented as from 2012. An exploration of antecedent or prior genre knowledge (Artemeva, N. \& Fox., J., 2010) was carried out in different workshops. Generic structure, audience awareness, rhetorical functions and linguistic features studied in the English courses were activated. Writing seminars in Spanish were implemented in $5^{\circ}$ year. In addition, undergraduates attended tutorials with the engineers and then and then interviews with the linguists. In several meetings students discussed titles and abstracts (in Spanish and English), designed their slides for the oral defense and rehearsed their oral presentations. The analysis of the corpus including all projects' titles defended within the time window that included our actions indicated that students had activated their previous generic knowledge. Feedback from students, after graduation, demonstrated that interdisciplinary activities included language as an across the curriculum content and contributed to the adequate production of academic genres. Results may affect curricular design and decisions at the macro level
\end{abstract}


since implementation of writing seminars along undergraduates' trajectories has been positioned as a top priority.

\section{Introduction}

Academic literacy in higher education has been the focus of many studies in Latin America during the last fifteen years. Thus, acquaintance with the discipline prototypical genres in order to meet academic exigencies is highly relevant for undergraduates (Arnoux, Di Stefano y Pereira, 2002). Although this issue has raised a lot of attention in Argentina, only a few universities offer writing courses in their curricula.

Students entering university are immersed into a new culture with its own ways of doing, being and saying, which entails acquiring skills to understand and produce the specific genres of the discourse community (Swales, 1990). Thus, they need to be equipped with strategies to become writers in their disciplines, both during their academic trajectory and later in their professional life.

The Faculty of Food Science, Universidad Nacional de Entre Ríos, Argentina, includes only one subject aimed at teaching academic reading and writing in the first year curricular design. The objective is to make students acquainted with some academic genres. When graduating, students have to write their Final Project (FP from henceforth. This is an extremely challenging task for them because they lack adequate writing strategies.

The Food Engineering FP, as its name implies, is a food manufacturing plant design or the development of a new food product project in which all aspects are considered and carefully described. This comprehensive study includes mathematical language, visuals and text. The Project Design and Assessment Department provides students with a set of instructions about WHAT to write. However, no instructions are given on HOW to write about the object of study.

Once these FPs title and abstract are uploaded to the faculty website, they gain wide visibility. An analysis of titles produced before our actions started indicated that practically no specific information to attract readers' interest was provided. Thus, Project Design and Assessment ( $5^{\circ}$ year, Food Engineering) and English II Course ( $3^{\circ}$ year) professors designed an interdisciplinary project focusing on the the required writing strategies.

Therefore, the aim of this paper is to describe a study performed by the aforementioned departments in order to explore whether joint actions could have a positive impact on this genre production and improve title and abstract writing to attract readers.

\section{The Study}

\subsection{Theoretical Framework}

Our work is grounded in the English for Specific Purposes and the New Rhetoric genre traditions and influenced by the Writing Across the Curriculum (WAC) and Writing in the Disciplines (WID) movements, led by Charles Bazerman (1988, 2005). Hyon, S. (1996), quoted by Swales, J. (2009), states that

...many ESP scholars have paid particular attention to detailing the formal characteristics of genres while focusing less on the specialized functions of texts and their surrounding social contexts" (p. 695). In contrast, New Rhetoric scholars "have focused more on the situational contexts in which genres occur than on their forms and have placed special emphases on the special purposes, or actions, that these genres fulfill within these situations (p.696). 
The ESP tradition (Swales J., 1990, 2004) fosters explicit genre instruction in order to promote students' written production during their academic trajectory. This school asserts that genre acquisition empowers socially and linguistically deprived students to access ways of communication included in the cultural capital owned by social, professional, academic and occupational communities. Hyland (2003) states that a "visible pedagogy" offers an explicit understanding of how target texts are structured and why they are written in such a way. Cope \& Kalantzis (in Bawarshi \& Reiff, 2010) add that an explicit focus on genres during the literacy process reveals the existing relationship between texts and their social objectives, thus enabling them to produce effective texts. Artemeva (2015) states that advanced students become aware of the socio-rhetorical aspect of genres and thus, they may introduce changes that are accepted by the disciplinary community.

The New Rhetoric School focuses on the context and the social action deployed by genre (Miller, C., 1984). In this perspective, discourse genre is an abstract concept that instantiates social and textual ways of being, knowing and interacting within specific contexts.

ESP understands texts and their communicative objectives through the context while the New Rhetoric studies the context and social actions deployed by texts (Bawarshi \& Reiff, 2010). However, both schools agree on the conceptualization of genres as instantiation of social actions.

The studies of cyber-genres (Yates, J. and Orlikowski, W., 1992; Shepherd, M. and Watters, C., 1998) also influence this research since both dynamism and functionality have strongly affected genres. Evolution and adaptation of FP titles to the new medium have been an important reason for this study.

Disciplinary context specificity and the social forces that affect communication to develop the sense of audience impact on genre production (Wenger, E. 2000). Students, as Legitimate Peripheral Participants, LPP (Wenger, 1991) share time, knowledge, ways of doing and saying with experts, who assist them during their trajectory into the Community of Practice (Lave \& Wenger, 1991). Thus, professional identity is also developed while students get acquainted with the shared repertoire.

We agree with Ávila Reyes et al (2013) in that writing should be considered as an ability situated in a particular context, with real meaning and application to concrete situations.

Consequently, it is important to consider genre analysis as socially situated. This approach presents students with tasks that go beyond a mere linguistic description of genres towards an explanation of why some linguistic features and rhetorical functions are selected for genre instantiation. This study adopts John Swales' genre definition as a communicative event (1990) as the unifying concept. Since the focus is mainly on the discourse aspect of the FP production, this research is mostly qualitative in nature.

\subsection{Data Collection and Analysis}

All titles of FPs were collected manually. Every fifth title was selected to constitute what was defined as Corpus A (See a sample extract in Table 1). Soler's (1) (2007) classification of titles was applied. Results indicated that students needed to become aware of the function of titles in order to attract an important readership, particularly during an Internet search so as to make these studies visible. The analysis also showed that very few words were used with the Noun Group as the prevailing form. 


\begin{tabular}{|c|c|c|c|c|}
\hline Number & Graduation & Title & & \\
\hline 30 & 1993 & Egg powder & & \\
\hline 55 & 2001 & $\begin{array}{l}\text { Poultry processing } \\
\text { plant }\end{array}$ & & \\
\hline \multirow[t]{2}{*}{100} & 2009 & $\begin{array}{l}\text { Raw sunflower oil } \\
\text { manufacture }\end{array}$ & & \\
\hline & & Total: 25 titles & $\begin{array}{l}\text { Average: } \\
\text { 5,04 words }\end{array}$ & $\begin{array}{l}100 \% \\
\text { Noun } \\
\text { group }\end{array}$ \\
\hline
\end{tabular}

Table1. Sample extract, Corpus A

As a consequence of the analysis performed, both Departments (Project Design and Assessment, $5^{\circ}$ year and English II Course, $3^{\circ}$ year) designed a set of interdisciplinary pedagogical actions. These were carried out in order to raise awareness of the importance of producing academic genres adequately, facilitate acquisition and /or activation of writing strategies and produce effective titles and abstracts, both in Spanish and English.

\subsection{Pedagogical Actions}

- Interdisciplinary seminars dealing with the discourse aspect of the genre under study.

- Writing seminars in Spanish

\subsection{Interdisciplinary Seminars}

These seminars have been taught as from 2012 in $5^{\text {th }}$ year. Both engineer and linguist worked together to activate previous knowledge and to focus on the discourse perspective.

Different concepts taught in English were activated in Spanish. Topics included disciplinary culture (Hyland, K., 2000), Community of Practice (Lave \& Wenger, 1991), academic genres characteristics (Swales, 1990; Swales \& Feak,1994), disciplinary language (Hyland, 2005). The FP as a genre was explored, as well as differences and similarities between the FP and the Research Article. Both abstract and title of the FP were dealt with in respective seminars, with subsequent relevant tasks.

It was also necessary to implement Writing seminars in Spanish to deal with issues at the micro and macro writing levels in the mother tongue.

\subsection{Writing Seminars in Spanish}

These were delivered by a writing specialist. Different academic genres were reformulated focusing on micro writing issues and FP production. The students found tasks highly helpful.

We agree with Ávila et al (2013) who assert that (...) reading and writing should be included in the curricular design as epistemic tools, as a particular community written language facilitates, potentiates and consolidates learning and acquisition of both discipline contents as well as the discipline discourse conventions.

As a final task, a set of instructions on how to write the FP was produced collectively. They deal with the discourse aspect and complement instructions on the content to be included in the FP.

Academic literacy seminars in Spanish had a positive impact on students' writing. It was perceived that students had become aware of genres and their systems. They also realized the occurrence of occluded genres (Swales, 1990). Studies assert that this process is an essential component of the 
acculturation process within the disciplinary community (Artemeva, 2005, 2008). In addition, it includes the appropriation of the shared repertoire of the Community of Practice (Lave and Wenger, 2001).

\subsection{Writing Space and Final Project Preparation}

Tutorials, both face to face and online, were offered after the interdisciplinary and writing seminars were held and students were already writing their FP. During these face-to-face tutorials, different titles were discussed, assistance with edition of the final version was provided, the oral defense was prepared, slides were designed and the oral presentation was rehearsed. This writing tutorial space was generated to comply with students' requirements.

This interdisciplinary supportive space became a highly enriching interaction between students and teachers. Engineering and linguistic expertise (in Spanish and English) worked jointly as a team. Students felt more self- confident when they presented their FP. In addition, it was felt that the sum of both disciplines strengths in order to achieve a common objective tightened interpersonal links.

The feedback obtained from students when asked for suggestions to optimise our interdisciplinary activities was highly encouraging: they valued the support received to improve their FP writing and defense.

\subsection{Survey}

A survey was sent by email to recent graduates to get feedback about our interdisciplinary actions. The answers, along with the results obtained, enable a corroboration of our hypothesis: joint actions between engineers and linguists, with focus on the discourse aspect of FP title and abstract production, improves title writing, adding value to knowledge distribution.

\subsection{Corpus B Analysis}

It was constituted by all FP titles. The analysis was performed in 2015. An adaptation of Soler, V., (2007) and Labassi, T., (2009) classification of titles was applied. Soler's classification (2007), adapted from Haggan (2004), was first used to analyse Corpus A and then Corpus B to compare number of words and grammatical form used.

\section{Results and Discussion}

The implementation of interdisciplinary and complementary actions rendered significant results: different disciplines experts working together on a project with a common objective can attain results that tighten interpersonal links, strengthen students- teacher relations and foster teamwork. Engineers realized that they need linguists to provide the discursive aspect of academic genres. And linguists need engineers to provide the content, adequate comments about the accurate processes and equipment selected to write the FP, in agreement with the disciplinary community conventions. Exchanges between teachers and students preparing their graduation project spontaneously generated a supportive space where students were provided with assistance to write abstract and title, to prepare the oral defense, design the slides and rehearse the presentation. Feedback provided by a survey indicated $100 \%$ satisfaction with the interdisciplinary actions and the writing seminars. Students suggested these actions should be included in the curricular design.

The genre based approach used both in the English courses and the writing seminars in Spanish proved to be effective. Undergraduates realized that instantiation of genres by means of adequately 
written texts enables the access to the disciplinary community. Students were able to understand why texts are written the way they are, that is, they were able to go beyond a mere linguistic description.

Collaboration between professors fostered in turn, collaborative work among students. A highly significant production during last writing seminar in Spanish was a set of instructions on how to write the FP, following the structure provided. This document is under consideration to be included in the discipline curricular design.

Corpus A analysis showed a mean value of 5.04 words per title, while Corpus B showed an average of 17,91words per title (See Fig. 1). As for the grammatical form used, the difference shown by both corpora is quite significant. Corpus A displayed a $100 \%$ use of the Noun Group, while Corpus B, containing all titles produced after actions started, exhibited a diversification of forms: $25 \%$ Compound Titles and 75\% Noun Group. The use of a Compound Title (with a colon or semicolon) reveals the need to specify the topic.

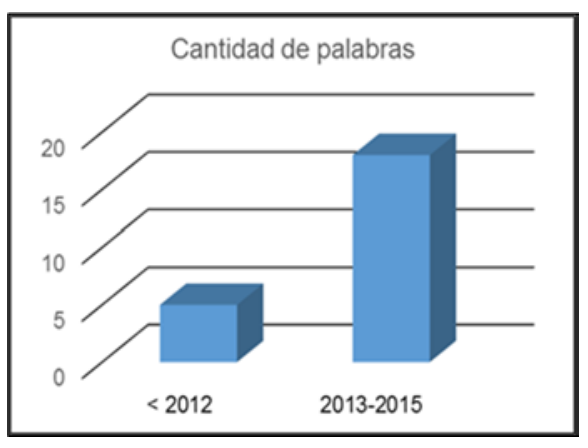

Figure 1: Number of words

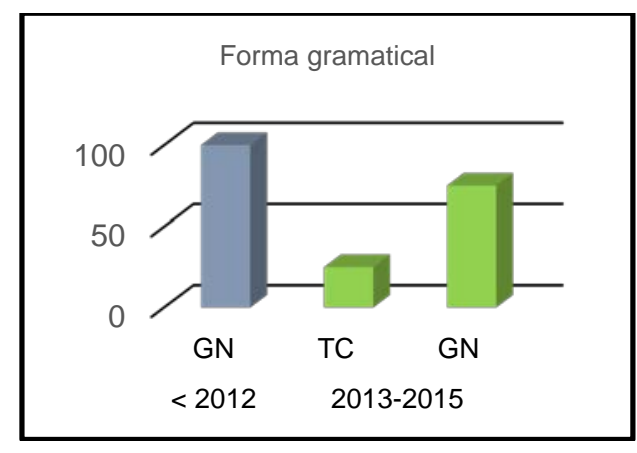

Figure 2: Grammatical form

Corpus B analysis showed that students had become aware of the importance of language as the indispensable tool to construct and distribute knowledge as an across the curriculum content. In addition, this corpus analysis suggested that there has been a process of sensitizing to rhetorical purpose by including more information in the titles, showing the process of distillation the study has gone through to present the work in an attractive, informative but concise way in keeping with science writing conventions.

\begin{tabular}{|l|c|l|}
\multicolumn{1}{l|}{ Number } & Grad & \multicolumn{1}{l}{ Title } \\
\hline 125 & 2015 & $\begin{array}{l}\text { Re-engineering a meat and sausage manufacturing plant as a result of the development } \\
\text { of a high yield cooked pork cut }\end{array}$ \\
\hline 126 & 2015 & $\begin{array}{l}\text { Manufacture of blueberry preserves from fruit unsuitable for fresh consumption as a } \\
\text { value added innovation. }\end{array}$ \\
\hline 127 & 2015 & $\begin{array}{l}\text { Entrerriana Winery:Industrial Plant for Manufacturing, Aging and bottling of fine wines } \\
\text { produced in Entre Ríos }\end{array}$ \\
\hline
\end{tabular}

Table 2. Sample extract. Corpus B 


\section{Conclusion}

Expected and unexpected results were obtained. Engineering and linguistic expertise at work together enabled writing to be viewed from a different perspective. It was evident that students became aware of the importance of language in knowledge construction. The set of instructions written by the students attending the writing seminars in Spanish on HOW to instantiate the engineering knowledge in the FP complements the instructions about WHAT to include in this genre.

Students realized the importance of including compact information load in the FP title to attract potential readers. In addition, they required the inclusion of the writing seminars in Spanish in their scheme of studies in order to facilitate the academic literacy process to Food Engineering undergraduates.

\section{Notes}

1. Soler's (2007) classification: noun group, compound titles, interrogative construction and sentence.

2. Original titles are in Spanish. Our translation.

3. Labassi's classification (2009): problem, hypothesis or theory to be assessed in the research; phenomenon or topic studied; methodology used in the study and brief description of results.

4. Adaptation of Labassi 's classification to our context and research objective: topic (type of industrial plant to be developed and/or raw material , location); methodology used/ developed to study a phenomenon/topic (description of study); description of results and/or mention of final product and combination of categories.

\section{References}

Arnoux, E., di Stefano, M. \& C. Pereira. (2002). La lectura y la escritura en la Universidad, Buenos Aires, Eudeba.

Artemeva, N. and D. N. Myles. (2015). Perceptions of Prior Genre Knowledge: A Case of Incipient

Billiterate Writers in the EAP Classroom. In Genre Trajectories Identifying, Mapping, Projecting EAP Classroom. Eds. G. Dowd \& N. Rulyova. ISBN: 978-1-137-50548-4 (Online)

Artemeva, N. and Janna Fox. 2010. Awareness versus Production: Probing Students' Antecedent

Genre Knowledge. In: Journal of Business and Technical Communication 24(4) 476-5152010 SAGE Publications. DOI: 10.1177/1050651910371302.

Artemeva Natasha. 2008. Toward a Unified Social Theory of Genre Learning. In: Journal of Business and Technical Communication. April 2008 22: 160-185, doi:10.1177/1050651907311925

Artemeva, N. 2005. A time to speak, a time to act: A Rhetorical Genre Analysis of a Novice Engineer's Calculated Risk Taking. In: Journal of Business and Technical Communication, 19(4), 389421.

Ávila Reyes, N.; González-Álvarez, P; Peñaloza Castillo, C. 2013. Creación de un programa de escritura en una universidad chilena: Estrategias para promover un cambio institucional. In: Revista Mexicana de Investigación Educativa, vol. 18, núm. 57, 2013, pp. 537-560. Consejo Mexicano de Investigación Educativa, A.C. Distrito Federal, México. (ISSN: 14056666). At: http://www.redalyc.org/pdf/140/14025774010.pdf

Bawarshi \& Reiff, eds. 2010. Genre: An Introduction to History, Theory, Research, and Pedagogy. At: http://wac.colostate.edu/books/bawarshi_reiff/

Bazerman, C. 1988. Shaping Written Knowledge: The Genre and Activity of the Experimental 
Articles in Science. Madison: University of Wisconsin Press, 1988.

Haggan, M. 2004. Research paper titles in literature, linguistics and science: dimensions of attraction. In: Journal of Pragmatics, 36. 2004. 293-317.

Hyland, Ken. 2005. Metadiscourse- Exploring Interaction in Writing. London, New York: Continuum

Hyland, Ken. 2003. Second Language Writing. Cambridge: Cambridge University Press

Hyland, Ken. 2000. Disciplinary Discourses. Harlow: Longman , Pearson Education Limited.

Hyon, S. 1996. Genre in three traditions: implications for ESL. In TESOL Quarterly, 30(4), 693722.

Labassi, Tahar. 2009. Reading Titles of Empirical Research Papers. In The Reading Matrix, Vol. 9, Number 2, September 2009.

Miller, C. 1984. Genre as Social Action, In: Freedman \& Medway, Eds. (1994) Genre and the New Rhetoric. London, Taylor \& Francis.

Lave,J.\& E.Wenger. 1991. Situated learning: Legitimate peripheral participation. Cambridge, UK. CUP.

Navarro, F. 2012. Alfabetización avanzada en la Argentina. Puntos de contacto con la enseñanzaaprendizaje de español académico como L2. In: Revista Nebrija de Lingüística Aplicada 12 (6): 49-83.

Shepherd, M. and Watters, C. 1998. The Functionality Attribute of Cybergenres. In Proceedings of the 31st Annual Hawaii International Conference on System Sciences, Maui, Hawaii, 1998.

Soler, V. 2007. Writing titles in science: An exploratory study. In: English for Specific Purposes 26. 2007. 90-102.

Swales, J. 1990. Genre Analysis: English in Academic and Research Settings. Cambridge, UK: Cambridge University Press.

Swales, J. 2004. Research Genres. Explorations and Applications. Cambridge: CUP.

Swales, J. and Christine B. Feak. 1994. Academic Writing for Graduate Students. Essential Tasks and Skills. A Course for Nonnative Speakers of English. Michigan series in english for Academic \& professional purposes. Series Editors: Carolyn G. Madden and John M. Swales.

Yates, J. y W. J. Orlikowski. 1992. Genres of organizational communication: A structural approach to studying communication and media. In: Academy of Management Review 17 (2): 299-326. 